\title{
Breast Imaging Findings among Asymptomatic Women who Underwent Screening Mammographic Examination in Port Harcourt, South-South, Nigeria
}

\author{
Awajimijan Nathaniel Mbaba ${ }^{1}$, Michael Promise Ogolodom ${ }^{2 *}$, Olukumi Yetunde Ijeruh ${ }^{1}$, Nengi \\ Alazigha1, Rufus Abam¹, Angel-Mary Chukwunyelu Anakwue ${ }^{3}$, Ebbi Donald Robinson ${ }^{1}$ and \\ Beatrice Ukamaka Maduka ${ }^{3}$
}

${ }^{1}$ Department of Radiology, Rivers State University Teaching Hospital, Nigeria

${ }^{2}$ Rivers State Hospitals Management Board, Nigeria

${ }^{3}$ Department of Medical Radiography and Radiological Sciences, University of Nigeria Enugu Campus, Nigeria.

*Corresponding author: Michael Promise Ogolodom, Rivers State Hospitals Management Board, Nigeria

To Cite This Article: Mbaba AN, Ogolodom MP, Ijeruh OY, Alazigha N, Abam R, Anakwue AC, Robinson ED, Maduka B U, et al., Breast Imaging Findings among Asymptomatic Women who Underwent Screening Mammographic Examination in Port Harcourt, South-South, Nigeria. 2020 - 8(6). AJBSR.MS.ID.001322. DOI: 10.34297/AJBSR.2020.08.001322.

Received: 㘹 April 28, 2020; Published: 制 May 07, 2020

\begin{abstract}
Background: Screening mammography contributes significantly to the reduction of breast

cancer-related morbidity and mortality through early detection and treatment. Breast cancer death is rising in Nigeria and over $70 \%$ of breast cancer patients present with advanced stages when no known remedy can annul disease advancement. This study was designed to document the findings of screening mammography of asymptomatic women to emphasize the role of screening mammography in early detection of breast cancer so as to encourage our women to embrace preventive care.
\end{abstract}

Materials and Methods: A total of 312 mammograms of asymptomatic women who presented

for breast cancer screening mammography at the women centre, Port Harcourt, Rivers State, Nigeria, between March 2018 and March 2019 were retrieved retrospectively. The mammograms were selected randomly based on the inclusion criteria, which are asymptomatic subjects. The mammograms were reported by three consultant radiologists with not less than five years' experience in breast imaging. Data were analyzed using descriptive statistics.

Results: Three hundred and twelve (312) adult women were screened. The mean and Standard

deviation of the age of the study population was $44.55 \pm 24.05$ years with age range of $26-75$ years.Most of the women were within the age group of $41-45$ years, $23.72 \%(n=74)$ and the least were within the age bracket of $26-30$ years, which is $0.32 \%(n=1)$.The commonest category of mammographic findings according to BI-RADS classification was BI-RADS 1,68.59\%(n=214) and the least was BI-RADS 0, which is 0.96\%(n=3).

Conclusion: This study showed that breast cancer screening mammography of asymptomatic Women is indispensable for early detection of breast cancer and women above 40 years of age are at increased risk of breast cancer.

Keywords: Asymptomatic Women, BI-RADS, Screening Mammography

\section{Introduction}

It has been documented that screening mammography contributes significantly to the reduction of breast cancer-related morbidity and mortality through early detection and treatment $[1,2]$. Although the negative effects of mammography cannot be completely overlooked, many countries have adopted breast cancer screening programs in order to detect breast cancer at an early stage [3]. In United States, most women older than 40 years take part in breast cancer screening exercises $[4,5]$.
Breast cancer is the most common type of cancer in women in developed and developing countries, [6] and constitutes the second most common cause of cancer-related deaths globally $[7,8]$. In subSaharan Africa, breast cancer is responsible for $25 \%$ of diagnosed cancers and $20 \%$ of cancer-related mortality amongst women [9]. The incidence of breast cancer is rising in Nigeria and over 70\% of breast cancer patients present with advanced stages when no known remedy can annul disease advancement $[10,11]$. There is a 
general increase in the incidence of breast cancer worldwide and WHO advocates that there will be a 70\% increase in the incidence of breast cancer by 2030 in developing countries [12], which call for improved breast cancer screening for early detection and treatment in these countries including Nigeria.

Mammography is the most effective tool for the early detection, characterization and evaluation of findings suggestive of breast cancer in asymptomatic women. Mammography uses low-dose x-radiation for early detection of breast cancer and in Nigeria women aged 40 to 70 years take part in screening [13], although may also be open to women less than 40 years with strong family history [14]. It is also an established fact that in Nigeria the peak age of breast cancer is about 10 years earlier than that of Caucasians $[10,11]$.

Mammography has an estimated sensitivity about of $75 \%$ to $90 \%$ with specificity of $90 \%$ to $95 \%$ [15], and to ambiguity and standardize breast imaging reporting for mammography, ultrasound and Magnetic Resonance Imaging (MRI), American College of Radiologists (ACR) introduced Breast Imaging-Reporting and Data System(BI-RADS) [16,17]. The BI-RADS has undergone changes and the latest edition, which is the 5th edition, published in 2013 [18], categorize breast lesions into BI-RADS 0- indeterminate, BI-RADS 1-negative, BI-RADS 2-benign, BI-RADS 3-probably benign, BI-RADS 4-suspicious for malignancy, BI-RADS 5-highly suggestive of malignancy and BI-RADS 6-known biopsy-proven malignancy. The vast majority of screening mammograms fall into BI-RADS 1 or 2 [19].

Mammography screening of asymptomatic women is not routinely done in this environment due to lack of sustained national programs [20], consequently the immense capabilities and benefits of screening mammography are not well appreciated and breast cancer is a common finding in our women. There is paucity of data on screening mammography of asymptomatic women in our setting. This study aimed to document the findings of screening mammography of asymptomatic women to emphasize the role of screening mammography in early detection of breast cancer so as to encourage our women to embrace preventive care.

\section{Materials and Methods}

A total of 312 mammograms of asymptomatic women who presented for breast cancer screening mammography at the women centre, Port Harcourt, Rivers State, Nigeria, between March 2018 and March 2019, run by the Medical Women's Association of Nigeria (MWAN), Rivers State chapter were retrieved retrospectively. Standard protocols and techniques were adopted by mammographers to obtain the mammograms using PHILIPS Microdose SI L50-U mammography machines. Ethical approval was obtained from the Research Review Committee of the study centre. All information obtained were treated with high confidentiality and used for the purpose of the study only. The mammograms were selected randomly based on the inclusion criteria, which are asymptomatic subjects and were reported by three consultant radiologists with not less than five years' experience in breast imaging. The final findings were categorized according to the American College of Radiology, Breast Imaging and Data Systems(ACR- BI-RADS).The generated data were collected using data capture sheet and process using SPSS version 21. Data were analyzed using descriptive statistics (tables, frequency, percentages, mean and standard deviation).

\section{Results}

A total of three hundred and twelve (312) adult women were screened. The mean and Standard deviation of the age of the study population was $44.55 \pm 24.05$ years with age range of 2675 years. Most of the women were within the age group of 4145 years, $23.72 \%(n=74)$, followed by age group 51-56 years, $16.99 \%(n=53)$ and the least were within the age bracket of 26-30 years, which is $0.32 \%(n=1)$ (Table 1$)$. Women with age $\leq 40$ years accounted for $19.56 \%$ of the total population while those above 40 years of age accounted for the remaining $80.44 \%$ (Table 1 ). The commonest category of mammographic findings according to BIRADS classification was BI-RADS 1, $68.59 \%(n=214)$ followed by BI-RADS 2, 25.96\% ( $\mathrm{n}=81)$ and the least was BI-RADS 0, which is $0.96 \%(n=3)$ (Figure 1).

Table 1: Number and percentage distribution of the subjects across the various age groups

\begin{tabular}{|c|c|c|}
\hline Age group (Years) & Number of participants & Percentage (\%) \\
\hline $26-30$ & 1 & 0.32 \\
\hline $31-35$ & 11 & 15.53 \\
\hline $36-40$ & 49 & 23.72 \\
\hline $41-45$ & 74 & 15.71 \\
\hline $46-50$ & 49 & 16.99 \\
\hline $51-55$ & 53 & 9.3 \\
\hline $56-60$ & 29 & 7.05 \\
\hline $61-65$ & 22 & 4.14 \\
\hline
\end{tabular}




\begin{tabular}{|c|c|c|}
\hline $71-75$ & 11 & 3.53 \\
\hline Total & 312 & 100 \\
\hline
\end{tabular}

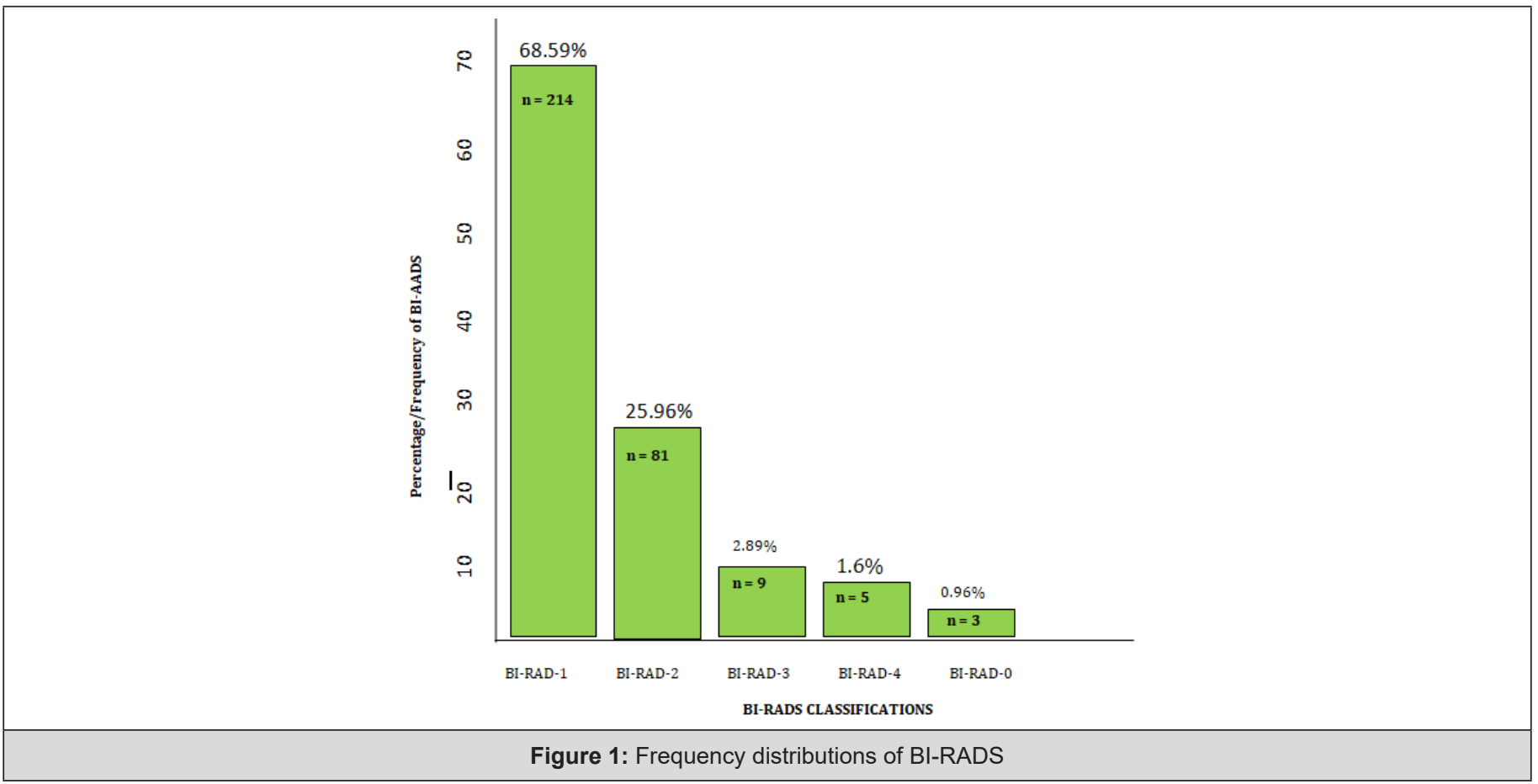

\section{Discussion}

Mammography is an essential screening imaging tool for early detection of breast cancer. The screening of asymptomatic women is not routinely carried out in our environment due to lack of sustained national program [20].

In this present study, greater numbers of the subjects were those above 40 years of age, which accounted for over $80 \%$ of the total population with peak percentage found in 41-45 years age group. This finding is in agreement with the findings of similar studies conducted by Umeh et al. [21] in South-east Nigeria, Akhigbe et al. [14] in Benin City and Lagos, Nigeria, and Onwuchekwa and Alazigha [22].

The most common mammographic finding based on BIRAD classifications in this present study was BIRAD-1, which is negative/ normal mammographic findings. This finding is probably due to the nature of our study population, which were asymptomatic subjects who came for breast screening. This is consistent with the findings of the study conducted by Onwuchekwa and Alazigha [22], Akhigbe et al. [14] and Mohammed et al. [23]. In the study conducted by Onwuchekwa and Alazigha [22], reported BIRAD-1 to be highest, $58.49 \%(\mathrm{n}=155)$, BIRAD-2 $13.96 \%(\mathrm{n}=37)$ and the least was BIRAD-0, which was $0.75 \%(n=2)$. Akhigbe et al. [14] study in Benin and Lagos, Nigeria, reported BIRAD-1 to be $52.5 \%(n=127)$ and BIRAD-2 to be $19.47 \%(n=47)$. Mohammed et al. [23] also reported BIRAD-1 to be highest, which was $66.2 \%(n=51)$. The differences in our findings in terms of absolute values may be attributed to the different sample sizes and the nature of the study populations in the various studies. In contrary to our findings, Umeh et al. [21] in South-east Nigeria, reported BIRAD-2 to be highest, which was $36.4 \%$ ( $n=198)$. Also, Ebubedike et al. [24] in their study conducted in Nnewi, South-east, Nigeria, reported BIRAD-2 to be highest, $51.2 \%(n=22)$ out of 43 study population. Sample sizes recruited in our studies accounted greatly for the differences noticed in our findings.

Although, normal findings were highest mammographic findings based on BI-RADS classifications in this present study, BI-RAD-2, which represents benign findings were the commonest abnormal findings. This finding is in accordance with the findings of similar studies, which revealed that benign lesions are more frequent than the malignant lesions [25-27]. The BIRAD-4 classification, which is suspicious of malignancy accounted for only $1.6 \%(n=5)$ and was seen in women above 40 years of age. They were recommended for breast biopsy. This finding is consistent with the finding of the study conducted by Akhigbe et al. [14].

\section{Conclusion}

This study showed that breast cancer screening mammography of asymptomatic women is indispensable for early detection of breast cancer and women above 40 years of age are at increased risk of breast cancer. Based on the findings of this study we recommend that our women who are above the age of 40 years should embrace preventive care and avail themselves of the available mammographic services in our setting. 


\section{Acknowledgement}

The authors are grateful to the Medical Women's Association of Nigeria (MWAN) Rivers State Chapter for providing access to their data base for the purpose of this study.

\section{References}

1. Dowling EC, Klabunde C, Patnick J, Ballard Barbash R, International Cancer Screening Network (ICSN) (2010) Breast and cervical cancer screening programme implementation in 16 countries. J Med Screen 17(3): $139-146$

2. Humphrey LL, Helfand M, Chan BK, Woolf SH (2002) Breast cancer screening: a summary of the evidence for the U.S. Preventive Services Task Force. Ann Intern Med 137: 347-360.

3. Nederend j, Duijim LEM, Voogd AC, Groenewoud JH, Jansen, et al. (2012) Trends in incidence and detection of advanced breast cancer at biennial screening mammography in the Nrtherlands: a population based study. Breast Cancer Res 14(1): R10.

4. Elmore JG, Armstrong K, Lehman CD, Fletcher SW (2005) Screening for Breast Cancer. JAMA 293(10): 1245-1256.

5. Weir HK, Thun MJ, Hankey BF, Ries LAG, Howe HL, et al. (2003) Annual report to the nation on the status of cancer, 1975-2000, featuring the uses of surveillance data for cancer prevention and control. J Natl Cancer Inst 95(17): 1276-1299.

6. Naghibi SA, Jamshidi P, Yazdani J, Rostami F (2016) Identification of factors associated with breast cancer screening based on the PEN-3 model among female school teachers in Kermanshah. Iran J Health Educ Health Promot 4(1): 58-64.

7. Okobia MN, Bunker CH, Okonofua FE, Osime U (2006) Knowledge, attitude and practice of Nigerian women towards breast cancer: A cross-sectional study. World J Surg Oncol 4:11.

8. Parkin DM, Bray F, Ferlay J, Pisani P (2005) Global cancer statistics,2002. CA Cancer J Clin 55(2): 74-108.

9. Ferlay J, Shin HR, Bray F, Forman D, Mathers C, et al. (2010) Estimates of worldwide burden of cancer in 2008: GLOBOCAN 2008. Int J Cancer 127(12): 2893-2917.

10. Okobia MN, Osime U (2001) Clinicopathological study of carcinoma of the breast in Benin City. Afr J Reprod Health 5(2): 56-62.

11. Anyanwu SN (2000) Breast cancer in eastern Nigeria: a ten year review. West Afr J Med 19(2): 120-125.

12. Boyle P, Levin B (2008) World cancer report. Lyon, France: International Agency for Research on Cancer.
13. Lawal O, Murphy FJ, Hogg P, Irurhe N, Nightingale J (2015) Mammography screening in Nigeria - A critical comparison to other countries. Radiography 21(4): 348-351.

14. Akhigbe AO, Akinola RA, Ighodaro EO (2017) Screening mammography findings among some Nigerian women. J Adv Med Med Res 24(6): 1-7.

15. Ferrini R, Mannino E, Ramsdell E, Hill L (1996) Screening Mammography for breast Cancer: American College of Preventive Medicine Practice Policy Statement. American Journal of Preventive Medicine 12(5): 340341.

16. Michael JM (2002) The breast. Sutton D, editor. Textbook of Radiology and Imaging. $7^{\text {th }}$ edn, Churchill Livingstone, London, p: 1451-1488.

17. Weinstein SP (2006) Screening and diagnostic mammography. In: Pretorius ES, Solomon JA, editors. Radiology Secrets. $2^{\text {nd }}$ edn, Vol. 2. Mosby Elsevier, Philadelphia , USA, p: 33-57.

18. D’Orsi CJ, Sickles EA, Mendelson EB, Morris EA, et al. (2013) ACR BIRADS® Atlas, Breast Imaging Reporting and Data System. Reston VA, American College of Radiology.

19. Lazarus E, Mainiero MB, Schepps B, Koelliker SL, Livingston LS (2006) BI-RADS lexicon for US and mammography: interobserver variability and positive predictive value. Radiology 239(2): 385-391.

20. Bello M (2012) Awareness is the first step in battle against breast cancer. Bull World Health Organ 90(3): 164-165.

21. Umeh EO, Ebubedike UR, Nwammuo BC (2019) Suspicious and malignant features on mammogram among women in a group of communities within south east Nigeria. Int J Med Health Dev 24(1): 23-27.

22. Onwuchekwa CR, Alazigha NS (2018) Mammographic findings among Women in Port Harcourt: a Multicentre Study. Nigerian Health Journal 28(2): 1-7.

23. Muhammad SB, Saidu SA, Maaji SM, Musa A, Ibrahim HG, et al. (2019) Mammographic screening patterns in Sokoto, Northwestern Nigeria. Sahel Med J 22(1): 23-27.

24. Ebubedike UR, Umeh EO, C Anyanwu SN (2018) Mammographic findings of breast cancer screening in patients with positive family history in South-East Nigeria. Niger J Clin Pract 21(6): 801-806.

25. Starvos AT, Thickman D, Rapp CL, Dennis MA, Parker HA, et al. (1995) Solid breast nodules: Use of Sonography to distinguish between benign and malignant lesions. Radiology 196(1): 123-134.

26. Akande HJ, Olafimihan BB, Oyinloye OI (2015) A five-year audit of mammography in a tertiary hospital, North Central, Nigeria. Niger Med J 56(3): 213-217

27. Ochicha O, Edino SI, Mohammed AZ, Amin SN (2002) Benign breast lesions in Kano, Nig. J Surg Res 24: 257-262. 